\title{
Perspectivas para la historia de la medicina judía española
}

\author{
RON BARKAl *
}

\section{¿POR QUÉ UNA HISTORIA DE LA MEDICINA JUDÍA?}

a) En las dos últimas décadas, la historia de la medicina pasó a ocupar lugar de preferencia en el campo de la historiografía. La historia de la medicina se reveló como una parte importante, no sólo para la historia de la ciencia, sino también para los diferentes aspectos de lo que llamamos «la historia general». Los trabajos de G. E. R. Lloyd destacan la importancia de las dimensiones «non-científicas», como la mentalidad popular, la ideología de la clase dominante, en el pensamiento considerado "puramente científico" '. Un libro recientemente publicado por Danielle Jacquart y Françoise Micheau, trata de los problemas de transmisión del saber científico de una cultura a otra ${ }^{2}$. El libro intenta analizar cuáles son las condiciones y las formas de este tipo de transmisión, las vías de aceptación y de asimilación de ideas y concepciones ajenas ${ }^{3}$. Evidentemente, las conclusiones de la búsqueda en el campo de la medicina, son válidas para otras ramas de la ciencia y el pensamiento.

b) Se puede presentar una cuestión justificada: ¿Hay medicina judía? ¿Los médicos judíos han tenido diagnósticos y medios de curamiento diferentes de los empleados por los médicos musulmanes o los cristianos? Si nos referimos a la medicina judía como literatura científica, escrita en «lenguas judías", judeo-árabe, hebreo, judeo-español, la respuesta sería más sencilla. Sin embargo, me parece que se puede hablar de medicina árabe, medicina latina-cristiana y de medicina judía. Es verdad que desde

Universidad de Tel-Aviv.

LLoYD, G. E. R., Science, folklore and ideology. Cambridge 1983.

JACQUART, D. y MICHEAU, F., La médecine arabe et l'occident médiéval. Paris 1990.

BARKAl, R., Les infortunes de Dinah, ou gynécologie juive au moyen âge. Paris 1991. 
un punto de vista estrictamente curativo, la base de la medicina de las tres culturas monoteístas en la Edad Media era la tradición médica griega. Las diferencias se aclaran cuando comparamos las diversas tendencias en cada cultura ${ }^{4}$. Por ejemplo, los autores árabes prefirieron, generalmente, tratados médicos enciclopedistas, en los cuales se encuentra todo el saber médico necesario. Los latinos, al contrario (al menos hasta los siglos XII-XIII), escribieron libros médicos especializados, dedicados a un tema: ginecología, oftalmología, etc. Los médicos judíos han compuesto los dos géneros de tratados médicos. Los árabes han galenizado completamente el arte de la medicina, mientras que en la medicina latina y hebrea existen importantes influencias de otras escuelas médicas, como la escuela metodista ${ }^{5}$. Finalmente, es evidente que cada cultura encontró y asimiló la medicina griega por medios lingüísticos, tradiciones y conceptos religiosos de su propia herencia. La investigación de la medicina judía en la España medieval es doblemente compleja: los médicos judíos se encuentran en el medio de este círculo de transmisión multicultural, griego, árabe, latino; hispano (ya sea castellano o catalán) y hebreo. Como veremos más adelante, no sólo se trata de la traducción y creación de términos indispensables de anatomía, fisiología, etiología, farmacéutica e instrumentos médicos, sino también de una mentalidad, a veces fundamentalmente distinta.

c) La historia de la medicina nos ofrece también un estudio histórico sociológico o histórico-antropológico. Uno de los trabajos más notables de este tipo es el libro de Luis García Ballester, sobre la medicina moris$\mathrm{ca}^{6}$. En este libro, el autor realiza un análisis histórico antropológico de la sociedad morisca, su mentalidad y su vida a través de la práctica médica, la tradición médica y la condición social del curandero morisco. El mismo método puede ser aplicado a cualquier sociedad, quizás al estudio de los judeo-conversos en especial. Para terminar esta parte de "elogio" de la historia de la medicina, quiero señalar que la medicina más que otras ramas de la ciencia se refiere directamente a la condición humana, a la enfermedad y a la salud. Por esta razón la actitud hacia la medicina en la sociedad medieval, y especialmente en la sociedad judeo española, era básicamente diferente de ia actitud hacia las «ciencias extranjeras» en general. En los debates más ardientes entre los «racionalistas» y «tradicionalistas», la medicina fue excluida de la polémica. Aún las prohibiciones

Para una discusión más amplia del problema véase: ibidem, págs. 7-10.

JaCQUART y MICHEAU, La médecine arabe, págs. 55-85.

- García Ballester, L., Los moriscos y la medicina. Un capítulo de la medicina y la ciencia marginadas en la España del siglo XVI. Barcelona 1984. 
del estudio de las ciencias, formuladas en la Edad Media, permiten el estudio de la medicina y sus ciencias aliadas ${ }^{7}$. El único campo en el cual se podía transgredir los preceptos del judaísmo - como el uso de materiales impuros, el empleo de prácticas mágicas - era la medicina ${ }^{8}$. La historia de la medicina, pues, nos da una dimensión nueva sobre el conflicto entre la razón y la fe; nos posibilita comprender la importancia de pensamiento mágico en el marco de las ciencias y el pensamiento tradicional ${ }^{9}$.

\section{LA CONDICIÓN ACTUAL DEL ESTUDIO DE LA MEDICINA JUDÍA EN LA PENINSSULA IBÉRICA}

a) En primer lugar, me parece que falta una bibliografía actualizada de los trabajos publicados sobre nuestro tema. La última bibliografía fue editada por R. Y. Ebied en $1971^{10}$. Esta bibliografía, dedicada a la medicina árabe y judía en la Edad Media, no era completa tampoco en el momento de su publicación. Necesitamos también una información accesible de las investigaciones en que se está trabajando. Obviamente, la bibliografía y la información necesaria tienen que ser efectuadas por medio de computadoras. Paradójicamente esta compilación no es difícil de llevar a cabo: la cantidad de las publicaciones es limitada, según mi conocimiento tampoco mucha gente dedica su trabajo de investigación a este campo.

Un breve examen de lo publicado hasta el presente revela un fenómeno instructivo: la gran mayoría es acerca de médicos judíos que actuaban en España y Portugal, en cambio los trabajos que analizan los tratados médicos mismos o sus ediciones críticas son escasos. Evidentemente, es más fácil acumular informaciones sogre algunos ilustres médicos judíos, que completar un trabajo de fondo, comparación de manuscritos, análisis de contenido y de términos en las diversas lenguas empleadas en estos manuscritos. Un análisis sociológico-histórico de los médicos judíos españoles, su papel en la sociedad judía y en el medio cristiano es indispensable, pero hasta ahora casi todos los trabajos se limitan a una descripción de algunos de estos médicos y sus actividades.

BARKal, Les infortunes de Dinah, págs. 99-102.

Ibidem, págs. 100-103.

Ibidem, "L'ús dels salms en la màgia jueva de l'edat mitjana i el Renaixement: El llibbre Shimush tehillim», en La Càbala. Barcelona 1989, págs. 17-57.

10 EBIED, R. Y., Bibliography of Medieval Arabic and Jewish medicine and Allied Sciences. Londres 1971. 
b) El trabajo de referencia más importante hasta hoy fue realizado a fines del siglo xIX por Moritz Steinschneider. El gran erudito alemán de la literatura árabe y hebrea completó una obra monumental en sus libros y artículos, en los cuales muestra un interés especial por la historia de la medicina ${ }^{11}$. Pero esta obra de Steinschneider, que examinó cientos de manuscritos hebreos y árabes, tiene sus límites, que parecen más claros con el progreso en el análisis y la publicación de los manuscritos descritos por él. Su método de trabajo consistía en la identificación de los manuscritos según el incipit y el colofón. El problema es mucho más complejo cuando falta el colofón. En estos casos, que son numerosos, Steinschneider, que contó con el tiempo necesario para leer los manuscritos enteros atentamente, nos ofrece una descripción e identificación bastante imprecisa. También cuando el colofón existe, la identificación de Steinschneider en algunos casos es errónea o sospechosa ${ }^{12}$. No es mi intención aquí criticar a Steinschneider, por el cual siento una gran admiración, sino insistir en que su trabajo puede servirnos como punto de partida o referencia, pero no podríamos avanzar en la investigación en este campo sin un análisis detallado de los manuscritos.

c) Maimónides es, sin duda, el médico judíoespañol, o al menos de origen español, cuya obra médica fue objeto de mayor atención, tal vez exagerada. Las ediciones del trabajo médico de Maimónides son ejemplo clásico de la problemática de las ediciones de manuscritos. La edición crítica de su Sarh asmā al- uqqār («La explicación de los nombres de drogas»), que es un glosario de "materia médica», fue publicada por Max Meyerhof en $1940{ }^{13}$. La ventaja de esta edición es que Meyerhof la sitúa en el lugar que le corresponde dentro de la cadena del desarrollo de este género, desde Dioscorides (siglo । de la era cristiana), pasando por los

11 La obra de Steinschneider sobre la historia de la medicina y las ciencias de la naturaleza está descrita por GaRRISON, F. H., «Bibliography der arbeiten Moritz Steinschneider zur Geschichte der Medizin und der Naturwissenschaften", Archiv für Geschichte der Medizin, vol. XXV, 1932, págs. 249-278. Para la descripción de los manuscritos medievales véase su libro: Die hebräischen Usersetzungen des Mittelalters und die Juden als Dolmetscher, 2 vols. Berlin 1893; reimpresión: GRAZ, 1956.

${ }_{12}$ Así por ejemplo, el médico granadirio Semuel ibn Ayyub escribe al principio de su tratado sobre los hemorroides que él mismo compuso el libro, empleando la palabra hebrea ${ }^{\circ} a s i t i h u$ (literalmente: "yo le he hecho»). La interpretación de Steinschneider era que ibn Ayyub tradujo el tratado árabe de Maimonides. Una comparación de los dos tratados muestra que son muy diferentes. Pero incluso no necesitamos de la comparación para llegar a esta conclusión. Cuando ibn Ayyub y otros autores judíos querían decir que su obra era una traducción, empleaban generalmente la palabra hebrea he taqtihū, literalmente: «lo he copiado», pero en el hebreo medieval este vocablo significa también «copiar» de una lengua (extranjera) al hebreo.

${ }_{13}$ Šarh asma al- ${ }^{\circ}$ uqqãr, Un glossaire de matière médicale composé par Maīmonide. Texte publié pour la première fois par M. Meyerhof. El Cairo 1940. 
autores en lengua árabe, en el Oriente y en el Occidente, hasta nuestro autor. Después de un análisis del texto, muestra Meyerhof su influencia en las siguientes generaciones. La edición crítica del texto árabe mismo, es también muy correcta y de gran valor para los investigadores hasta hoy día. Lamentablemente, las ediciones de las traducciones hebreas de los textos médicos de Maimónides no corresponden a estos criterios científicos. En primer lugar, están basadas sólo en una parte muy limitada de los manuscritos conocidos, y se encuentran en ellos muchos errores ${ }^{14}$. En lo que se refiere al análisis de los textos y su valoración histórica predomina, en ellos un espíritu apologético, que aparta el sabio judío de su ambiente científico-cultural árabe o cristiano. Me parece que este tipo de ediciones es más dañoso que útil. Lo mismo se puede decir de las traducciones de la obra médica Maimondiana al inglés ${ }^{15}$.

Una contribución importante para la historia de la medicina en general y para la medicina judía en especial, es el trabajo conjunto de J. O. Leibowitz y $\mathrm{S}$. Marcus. Se trata de un libro de medicina experimental (práctica médica basada en la experiencia y no en una teoría general) atribuido a Abraham ibn ${ }^{\circ}$ Ezra $^{16}$. La importancia de la obra radica en la excelente edición crítica de los textos hebreos, y en el estudio introductivo de los autores sobre "La teoría médica, terapia racional y mágica» ${ }^{17}$. En este estudio analizan Leibowitz y Marcus la relación compleja entre la medicina "científica» o «teórica» y la medicina «experimental» y «mágica». Sin conocer el trabajo de Lloyd, antes mencionado, llegan los dos investigadores a conclusiones similares. Para la gente de la Edad Media, tanto en la práctica médica cotidiana como en los libros de instrucción medicinal, no existía una separación aguda entre los diferentes métodos de curamiento. Al contrario: los médicos han empleado, generalmente, la práctica científica y mágica ${ }^{18}$. Por otra parte, al comparar este texto con otros, llegamos a la conclusión de que numerosas prácticas mágicas similares eran corrientes en el seno del judaísmo, del Islam y del cristianismo, en España misma y fuera de la Península Ibérica. Este tratado nos ofrece una prueba

14 Para una bibliografía amplia de la obra de Maimónides, véase el libro de EBIED citado en el n. ${ }^{\circ}$ 10, págs. 110-116. Me refiero especialmente a las ediciones de $\mathrm{S}$. Muntner, citadas en esta bibliografía.

${ }^{15}$ F. Rosner se encargó a la traducción inglesa de los tratados de medicina de Maimónides. Vid.

16 Leibowitz, J. O. y Marcus, S., Sefer Hanisyonot. The book of medical experiences. Attributed to Abraham ibn Ezra. Jerusalén 1984.

17 Ibidem, págs. 11-95.

18 lbidem, págs. 24-32. 
más de que los médicos judíos utilizaban en su tratamiento materiales impuros, prohibidos por la ley judía ${ }^{19}$.

d) Poco trabajo fue realizado hasta ahora en el campo de las traducciones de tratados médicos del latín y árabe al hebreo. Estas traducciones tienen importancia especial, porque ellas responden no solamente a una curiosidad intelectual, sino también a una necesidad de la teoría y la práctica médica. Las traducciones sirven como manuales médicos y contribuyen al desarrollo de esta ciencia en la sociedad. Quiero ilustrar esta idea basándome en dos ejemplos de investigación, acabados recientemente. Benjamin Richler señaló el lugar prominente de la medicina de Avicenna en la medicina judía en la Edad Media y en el Renacimiento. Richler contó 111 manuscritos de traducción, completa o parcial, del Canon d el médico musulmán ${ }^{20}$. Infortunadamente no tenemos otros trabajos similares, pero es evidente que los médicos judíos de la época han preferido la teoría y la práctica médica de Avicenna a las otras. Esta información es importante para la comprensión del desarrollo de la medicina judía en ese período.

Otro médico musulmán que ha tenido un lugar importante en la medicina de la Edad Media es 'Alī ibn 'Abbās al-Maŷūī († 994). Su tratado Kitāb kāmil al-sinā̄ at al-țibbiyā, fue muy popular en el mundo musulmám, y después de su primera traducción al latín por Constantino el Africano en el siglo XI, ganó fama en los círculos médicos en el Occidente. Curiosamente, este tratado fue ignorado por los médicos judíos. Conocemos algunas versiones incompletas del libro en judeo-árabe, todas compiladas en el Oriente. La única huella del libro entre los judíos del Occidente, es la traducción hebrea de sólo un capítulo. Esta traducción no llamó la atención de los investigadores, que no conocían la identidad de su autor ni el lugar y fecha de su compilación. Aunque todo este capítulo, traducido del original árabe, tiene importancia primordial para la historia de la medicina hebrea medieval ${ }^{21}$. La primera pregunta que surge es ipor qué el traductor eligió este capítulo? Se trata de una descripción anatómica de-

\footnotetext{
19 Barkal, R., «A Medieval Hebrew treatise on Obstetrics», Medical History, vol. XXXIII, 1989, págs. 111-113.

20 RICHLER, B., «Manuscripts of Avicenna's canon in Hebrew translation: A revised and upto date list", Koroth, vol. VIII, 1982, págs. 145-168. Recientemente fue publicada la importante traducción hebrea de las Medicatione Parabole de Arnaldo de Vilanova junto con el original latín: Paniagua, J. A.; Ferre, L. y Feliú, E., Arnaldi de Villanova Opera Medica Omnia, VI, 1. Barcelona 1990.

21 BARKAI, R., «The Judeo-Arabic and Hebrew Vesions of al-Majūsī's Kitāb kāmil aș-4in ăcat at-țibbiya", en Constantine the African and "Alī ibn al-Abbās al-Majūsĩ. The Warburg Institute of London y C.N.R.S. (en prensa).
} 
tallada del cuerpo humano. En consecuencia, se encuentran ahí todos los términos anatómicos del léxico médico, términos de los que la lengua hebrea medieval carecía, por supuesto. Un estudio cuidadoso del manuscrito revela que el trabajo fue hecho por un judío español anónimo, a principios del siglo XII. La identificación del origen español del manuscrito es posible gracias a una palabra en romance que aparece en él. En la sección que trata de los huesos del pie, el autor se refiere al hueso de la planta del pie, llamada en árabe al- ${ }^{\circ} a z ̧ a m$ al-zūrqī (el hueso en forma de una barca). El traductor emplea el término ha-'eșem al-safünī, en otras palabras, para la materia utiliza una palabra hebrea y para la forma ha preferido una palabra árabe, sāfinna, similar al hebreo sefinah. A esta composición él añade su propia explicación: «que es una barca pequeña, como barqetah" ${ }^{22}$. El autor del hebreo, entonces, empleaba un vocablo de su ambiente, la palabra española barqueta, diminutivo de barca. Este ejemplo muestra la importancia de un análisis minucioso de los manuscritos: una palabra sola, en un manuscrito de 70 folios, puede resolver un problema importante. Por otra parte, la comparación de los términos de anatomía del capítulo traducido, con los términos empleados en tratados médicos hebreos más tardíos, nos inclina a pensar que el objetivo de esta traducción era la creación de un léxico hebreo de anatomía, al servicio de los autores y los médicos judíos. Como se sabe, el comienzo del siglo xII marca un giro en la historia de la ciencia judía. Los judíos habitantes de los territorios islámicos, en Oriente y Occidente, escribían sus libros científicos en lengua árabe y en judeoárabe. Para ellos, árabeparlantes, no era solamente más fácil y más cómodo expresarse acerca de materia científica en esta lengua, sino también consideraban el árabe como la lengua adecuada para exponer ideas científicas. El uso del hebreo se redujo a los ritos religiosos y a la poesía sacra y profana. Con el destierro de los judíos de al-Andalus, a fines del siglo $\mathrm{XI}, \mathrm{y}$, sobre todo, a mediados del siglo Xil, la mayoría de estos judíos se establecieron en países cristianos, especialmente en España y el sur de Francia. Naturalmente, los descendientes de los inmigrantes fueron perdiendo gradualmente el conocimiento de la lengua árabe. Las lenguas vernáculas remplazaban al árabe como lengua viva entre los judíos, que curiosamente prefirieron el hecho como lengua escrita ${ }^{23}$. No tengo conocimiento de un intento de explicación de este fenómeno del segundo renacimiento de la

22 Berlín, Bibliotheca Regia, Ms. or. qu. 513 (64), fol. 13.

23 Friedenwald, H., "The use of the Hebrew Language in Medical Literature", Bulletin of the Institute of the History of Medicine, n. ${ }^{\circ} 2,1934$, págs. 77-111; MUNTNER, S., La historia de la lengua hebrea en la enseñanza médica. Jerusalén 1940 (hebreo). 
lengua hebrea en la Edad Media (el primero es el empleo del hebreo en la poesía de los siglos $\mathrm{x}$-XI). Es un tema importante para una investigación futura, pero se encuentra fuera de nuestra materia. El hecho de que los judíos educados fueron en su mayoría bilingües o trilingües, explica la existencia de numerosos léxicos, en los cuales junto al hebreo figuran otras lenguas, como el latín, el árabe, el castellano, el catalán, el provenzal, etc. Sin duda alguna, en estos léxicos los términos de los varios campos de la medicina ocupan un lugar importante.

\section{PERSPECTIVAS DE FUTURAS INVESTIGACIONES}

Hay que distinguir entre dos géneros de trabajos en este campo: a) Historia de las ideas médicas, que se base en la investigación y el análisis de los textos médicos mismos, escritos por judíos, su contenido, su transmisión y su difusión. b) Historia social de la medicina judía española, es decir, la relación entre el médico culto y el curandero "popular», el papel del médico judío en su comunidad y en el medio de la sociedad hispana, en general. La fuente de ese trabajo son los diversos archivos: municipales, eclesiásticos, etc., y la rica literatura de la Responsa de los rabinos.

El medio de trabajo más útil para llevar a cabo la primera etapa, la publicación de ediciones críticas de los tratados médicos, es el Instituto de Nilicrofilms y Fotocopias de Manuscritos Hebreros, en la Biblioteca Nacional en Jerusalén. Este Instituto ofrece al investigador la colecçión más amplia de los textos hebreos y judeo-árabes, cuyos originales están dispersos en bibliotecas y archivos en el mundo entero. No menos valioso es el catálogo temático de este Instituto, aunque todavía no es completo.

Un trabajo muy extenso fue realizado en los últimos años por varios investigadores sobre el uso de manuscritos árabes por los médicos judíos en los territorios de la España cristiana. En sus primeros estudios, Luis García Ballester alegaba que los libros de medicina escritos en árabe fueron utilizados por ambos, mudéjares y judíos ${ }^{24}$. El estudio del holandés P. Sj. van Koningsveld, sobre los manuscritos árabes que circulaban en la España cristiana de la Edad Media ${ }^{25}$, Ilegó a las siguientes sorpren-

24 García Ballester, L., Historia social de la medicina en la España de los siglos xIII-xVI. I. La minoría musulmana y morisca. Madrid 1976, pág. 40; Los moriscos y la medicina, pág. 20; "Medical Sciences en 13th Century Castile: Problems and Prospects", Bulletin for the History of Medicine, vol. LXI, 1987, pág. 186.

${ }_{25}$ KoningsveLD, P. Sj. van, «Andalusian-Arabic Manuscripts from Christian Spain: A comparative, Intercultural Approach», Israel Oriental Studies,...; «Andalusian-Arabic Manuscripts from Medieval Christian Spain: Some Supplementary Notes", Festchr ift H. R. Singer. 
dentes conclusiones: "As far as one can tell from the matiriales presented, the Arabic medical and scientific Mss. of christian Spain almost exclusivily circulated in Jewish circles... Our information about the scribes, students and owners of the medical and scientific Mss. is in fact quiet detailed. Several Mss. copied for Jewish owners, were written by Muslim scribes living as war captives in Christian Spain... Other Mss. were written by Jewish scribes. Not only were many Mss. directly copied for Jewish owners, the also remained in Jewish ownership during following generations, as can gauged from the owner's entries" ${ }^{26}$. Estas importantes afirmaciones fueron aceptadas por García Ballester, en su último artículo, redactado en cooperación con Concepción Vázquez de Benito. Los autores especifican que de las tres minorías: musulmana, judía y mozárabe, «sólo de los miembros de la minoría judía tenemos pruebas de que, a lo largo del siglo XIV, conservaron el árabe culto e hicieron uso de él para acceder a la literatura médica redactada y conservada en árabe; una literatura médica de autores griegos (Hipó crates, Galeno), árabes (al-Rāzī, ibn Sinā, alMajūsī, al-Zahrāwī, y otros menores), y judíos (Maimónides), que ellos se preocuparon de copiar y transmitir»" ${ }^{27}$.

De todos los manuscritos médicos árabes que circulaban entre los judíos en el siglo XIV, el más original e interesante, desde el punto de vista de la creación de literatura médica es el Kitāb al-ț ibb al-gaš ț alī almalaki, escrito por un judío castellano anónimo. El manuscrito principal fue copiado en el año 1376 en Toledo por Mūsā ibn Sāsūn, probablemente miembro de una familia de médicos judíos toledanos, los Banū Šušān. García Ballester y Vázquez de Benito, en su estudio introductorio, destacan seis motivos de la importancia de este tratado: 1. Es la única muestra "que poseemos de producción intelectual de carácter médico», de un judío que vivió en la España cristiana en los años de transición del siglo XIII al XIV. 2. «Se trata de un producto intelectual muy elaborado... basado en el conocimiento directo del corpus médico de Galeno y de su amplio repertorio de obras médicas del galenismo árabe.» 3. «Por la estructura formal de la obra, el tema que aborda y el carácter didáctico de la misma, se trata de un escrito singular dentro de la literatura médica bajomedieval, tanto cristiana como árabe o judía...» 4. «La obra es resultado de la reflexión intelectual de un médico práctico judío, que ejerció entre los cristianos, que participó en las polémicas científico-médicas de su época...

26 loidem, pág. 3.

27 Garcia Ballester, L. y Vázquez de Benito, C., “Los médicos judíos castellanos del siglo XIV y el galenismo árabe: El Kităb al-ț ibb al-qaš ț alı al-malaki (Libro de medicina castellana regia) (c. 1312)", Asclepio, I, 1990, págs. 121-122. 
Además de este aspecto intelectual, su propia finalidad - eminentemente práctica- nos aporta material de primera mano para reconstruir el desconocido mundo de la práctica diaria de este período...» 5. «Al estar escrita en árabe, nos permite profundizar en el papel que el uso de esta lengua jugó en el conocimiento y elaboración de la ciencia médica... por parte de los miembros médicos de la minoría judía” de esta época. 6. «Pese a su carácter único, ello no quiere decir que fuera la única obra médica que se escribiera en el seno de las comunidades judías castellanas durante el siglo XIV» ${ }^{28}$. Concepción Vázquez de Benito está preparando una edición crítica de este libro tan importante para la historia de la ciencia en la España medieval.

Otro tratado médico judío, que tuvo influencia tanto en la medicina cristiana como en la musulmana, es el manuscrito hebreo titulado: Zikhron ha-holayim ha-hovim bi-khlei ha-herayon ("La mención de las enfermedades que ocurren en los miembros genitales») ${ }^{29}$. El manuscrito, que se conserva en la biblioteca del Jew College, en Londres, data del siglo $x v$. Del análisis del tratado llegó Steinschneider a la conclusión que se trata de una obra hebrea original, redactada en el siglo XII. En mi opinión, no hay duda que es un tratado hebreo original, pero me parece que fue compilado en el siglo xill, por las razones que he explicado en otro lugar. El examen de los términos médicos y farmacéuticos muestra que la obra fue escrita por un judío que vivió en un ambiente castellano, en tiempos en que la medicina árabe ejercía una fuerte influencia sobre los médicos judíos. La mayoría de los términos son traducción literaria del árabe o aparecen en árabe transliterado en letras hebreas. Se destaca el hecho de que el autor no se conformó con el vocabulario hebreo con que contaba y, por tanto, frecuentemente agregó, junto a los términos hebreos sus equivalentes árabes, o empleó exclusivamente los términos árabes. Así, por ejemplo, encontramos en los títulos de los capítulos: "Abundancia de menstruación y es una enfermedad llamada nazf»; "Sofocación del útero y es una dolencia parecia a șar $r^{\circ}$, que es epilepsia»; "Al-rạha, y es la enfermedad que la mujer parede encinta...». El autor no emplea la palabra hebrea lehah, que era común en la Edad Media para indicar "humor", en cambio usa constantemente el vocablo árabe jalt.

La influencia del romance se percibe en lo que atañe a los medicamentos. Por ejemplo, el autor utiliza el término ašarab, que es la forma

28 Ibidem, pág. 120.

29 BARKAI, R., "Dos capítulos de ginecología en árabe y castellano y otro en hebreo", Actas del VII encuentro de las tres culturas. Salamanca 1990 (en prensa). 
convencional en romance de la palabra árabe šarab (brebaje curativo); y usa constantemente el término romance pildolas (píldoras ). Podemos establecer que las dos lenguas, árabe y castellano, fueron empleadas por el autor al lado del hebreo, como medio de expresión legítimos, sin otorgar un valor preferencial a ninguna de ellas. Así encontramos frases como las siguientes: «ušnān [alcalí] que se llama erbah [sic!] dešawāq [de šawāq] en lengua extranjera». Es de mencionar que el término ušnān, pasó del árabe al castellano como expresión corriente ${ }^{30}$. En otra frase, en cambio, es el árabe considerado como lengua extranjera: «Sabinah que se llama en lengua extranjera al-abhal».

C. Vázquez de Benito y M. T. Herrera publicaron en 1981 un artículo en la revista Asclepio $^{31}$. En ese trabajo, las dos historiadoras de la medicina han comparado dos capítulos ginecológicos: Uno del autor granadino, Muhammad ben 'Abdallāh ben al-Ja t i ib (1313-1374), que aparece en su libro: 'Amal man ț abba līman ḥ abba; el otro de un castellano anónimo del siglo Xv: Tratado de patología general. Basándose en la comparación de ambos textos, las investigadoras llegaron a la siguiente conclusión: «... [el árabe] no es la fuente única [del castellano], bien puede haber sido uno de los más importantes ejes de la obra...». En un estudio detallado he señalado que la obra hebrea, fue probablemente la fuente principal de ambos, el árabe y el castellano.

Este último ejemplo demuestra que sólo un trabajo minucioso, históricofilológico, puede reconstruir el amplio cuadro de la medicina judía y su lugar en el conjunto de la medicina hispana medieval. Hace tiempo estoy preparando una edición crítica de algunos tratados ginecológicos hebreos de la Edad Media. Aparte de la obra antes mencionada, la publicación incluirá el tratado de S̈ešet Benvenisti, el Nas $i$ de la comunidad judía de Barcelona: Terufut le-herayon («Medicamentos para el embarazo") ${ }^{32}$. A diferencia de las otras obras mencionadas, el tratado de Benvenisti denota influencias cristianas: El rabino-médico no solamente utiliza términos latinos y catalanes, sino también emplea fórmulas mágicas, típicamente cristianas, $\sin$ censura ${ }^{33}$.

\footnotetext{
3o Vázquez de Benito, C. y Herrera, María Teresa, Los arabismos de los textos médicos latinos y castellanos de la Edad Media y de la Modernidad. Madrid 1989, pág. 278.

31 Idem, «Dos capítulos ginecológicos: árabe y castellano», Asclepio, vol. XXXIII, 1981, págs. 183-241.

32 Bodleian Library, Oxford, ms. or. 2142.

${ }_{33}$ Por ejemplo la receta para curar el útero seco: "fiat electuarium ad modum manum ch ristum», esta fórmula también escrita en letras hebreas. Ibidem, fol. $253 \mathrm{v}$.
} 
Uno de los tratados médicos judíos más importantes del siglo $x \mathrm{~V}$ es Guerem ha-ma ${ }^{c}$ alot, de Yehošu ${ }^{\mathrm{c}}$ ha Lorī ${ }^{34}$. El autor, uno de los sabios más destacados de la comunidad judía española de su época, escribió su libro en árabe, y lo ha traducido al hebreo Yosef Vidal ben Benvenisti ben Leví. Guerem ha-ma ${ }^{\mathrm{c}}$ alot circulaba en España y fuera de la Península con mucho éxito. A primera vista parece extraño que hasta el momento no tengamos un estudio digno ni una edición crítica de los numerosos manuscritos del libro. Aún Y. Baer, que dedica un capítulo entero a Yehošu ${ }^{\circ}$ ha-Lorqi en su libro sobre los judíos en la España cristiana, se contenta con señalar en pocas palabras que él fue «médico y autor científico", sin mencionar su importante tratado ${ }^{35}$. El fenómeno puede explicarse por la personalidad del autor y su historia. Ese personaje, que era el médico personal del Papa Benedicto XIII, se convirtió al cristianismo y eligió su nombre de bautismo Jerónimo de Santa Fe. Después de su conversión tomó parte muy activa en la polémica anti-judía que llegó a su punto máximo en la Disputa de Tortosa (1413-1414). Los historiadores del judaísmo español, que de cualquier manera tienen interés muy limitado en la historia de la medicina, preferían ignorar completamente la obra científica del converso. El cargo completo de preparar un estudio del contenido científico del Guerem ha-ma ${ }^{c}$ alot y su edición crítica, lo está llevando a cabo un estudiante de Doctorado del Departamento de Hebreo y Arameo de la Universidad Complutense.

Una fuente valiosa para comprender la actitud de los judíos hacia la medicina, como un componente de las "ciencias extranjeras" o las ciencias profanas, la constituyen las introducciones de los autores, los traductores y los copistas de los libros médicos. En ese género literario se expresan los autores y reflejan las diversas opiniones que circulaban en la comunidad judía sobre el tema. Un trabajo pionero de este tipo fue realizado en conjunto por tres investigadores: L. García Ballester, Lora Ferre y Eduard Feliu ${ }^{36}$. Aunque tengo bastantes desacuerdos con sus conclusiones, el método de este trabajo debe servir de modelo para una futura investigación.

Un estudio histórico-sociológico sobre los judíos y la medicina en la Corona de Aragón (1280-1400) está realizado en los últimos años por dos especialistas de la historia de la medicina en la España medieval: L. García

${ }^{34}$ Sobre este autor véase BAER, Y., Historia de los judios en la España cristiana. Tel Aviv 1959, págs. 308-346. Hay una traducción castellana publicada en Madrid 1981.

35 Ibidem, pág. 308.

36 Garcia Ballester, L.; Ferre, L. y Feliú, E., «The Jewish Rationalists' Attitude Towards 14th Century Scholastic Medicine», Osiris, 1990. 
Ballester y M. R. Macaugh ${ }^{37}$. De la calidad científica de los trabajos anteriores de los dos historiadores, que colaboran desde hace muchos años, y de la abundante documentación que se encuentra en los archivos dispersos en el territorio de este reino, podemos esperar a un trabajo ejemplar. Aparte de los aspectos sociales y legales de la actividad de los médicos judíos aragoneses (su papel en la población cristiana, su relación con las autoridades securales y eclesiásticas y con médicos de otras religiones), se puede esperar que ese estudio nos ofrezca datos importantes sobre la práctica médica misma, la asistencia médica en los centros urbanos y, quizás también, en las regiones rurales.

\section{CIENCIAS ALIADAS A LA MEDICINA}

El estudio de la historia de la medicina necesariamente incluye otras ramas de las ciencias medievales, que se refieren directa o indirectamente a la medicina. La importancia del estudio de la farmacología es evidente; sin embargo, hay otros campos que han tenido una relación estrecha con la medicina "teórica" o con la medicina "alternativa». La astrología fue considerada en la Edad Media no solamente como una profesión académica, sino también fue en las escuelas de medicina un estudio obligatorio para los estudiantes de medicina. El médico medieval debía consultar los astros y tener en cuenta la situación del zodíaco durante todo el proceso del tratamiento: la diagnosis de la enfermedad, el examen del enfermo, la decisión del tipo de tratamiento, la elección de las materias para preparar los medicamentos y para fijar el tiempo propio de tratamiento, que sea por medio de medicamentos o por sangría. Judíos españoles, como Abraham ibn 'Ezra y Abraham bar Hiya, fueron considerados entre los astrólogos españoles más destacados hasta el siglo $\mathrm{XV}{ }^{38}$. La investigación moderna dedicó una atención considerable a la obra científica de estos dos sabios judíos. Sin embargo, hay una cantidad considerable de manuscritos hebreos astrológicos y astrológicos-médicos, probablemente una parte de ellos procedentes de España. La parte más estudiada de la astrológica judía hasta ahora no se refiere directamente a los textos astrológicos mismos, sino a la polémica sobre su validez científica y la actitud de la religión hacia este método. Nos falta, entonces, un estudio basado en los manuscritos astrológico- médicos, sobre la

${ }^{37}$ Asclepio, 1990, pág. 144, n. 5.

${ }^{38}$ BARKAl, R., "Astrologie juive au moyen âge: aspects théoriques et pratique», Le Moyen Ǎge, vol. LXXXXIII, 1987, págs. 323-348. 
práctica astrológica, el funcionamiento de la astrología en la vida diaria del judío medieval.

Contrariamente a la idea aceptada hace poco tiempo de que los judíos no necesitaban la magia, sabemos hoy que la práctica mágica, en varios aspectos de la vida, y sobre todo como uno de los métodos de la «medicina alternativa», era muy corriente entre los judíos españoles. El campo de la magia es muy extenso, la cantidad de los manuscritos mágicos, en formas de tratados completos o folios dispersos, es enorme. Quisiera presentar brevemente dos géneros de tratados que pertenecen a ese campo. Hace varios años que trabajo sobre el tratado mágico, probablemente más popular entre los judíos en la Edad Media y el Renacimiento: Sefer šimuš tehilim (El libro de uso [mágico] de los salmos) ${ }^{39}$. Cuando empecé el estudio conocíamos sólo ocho manuscritos de distintas versiones del tratado. Hoy conozco más de treinta, y últimamente descubrí algunos manuscritos en latín, en el dialecto veneciano y en árabe. El estudio de los tratados muestra que por lo menos veinticinco por ciento de las prácticas mágicas registradas son dedicadas a la terapia médica, física o psicológica. El análisis de las diferentes versiones nos lleva a la conclusión de que la versión original era la española, que es también la versión más compleja e interesante desde el punto de vista de los métodos mágicos empleados. Por la cantidad de los manuscritos y las dificultades que proponen, estimo que necesito al menos tres años más para acabar este trabajo.

El uso de los miembros de animales, como procedimiento mágicocurativo, es conocido desde época antigua. Según los manuscritos hebreos existentes, titulados: Las virtudes de las partes de los animales, tengo la impresión que la misma práctica mágica fue utilizada por los judíos medievales, incluso en España. La búsqueda de estos manuscritos: el primero -ya mencionado-, el terapéutico, el valor médico de cada parte de los diferentes animales, incluso en muchos casos animales impuros según la ley judía. El segundo es el zoológico. Los tratados nos revelan las percepciones y las imágenes que el hombre medieval tenía de los diversos animales, en términos de valores humanos o mitológicos. El estudio de los documentos de la Gueniza hecho en los últimos años en Cambridge, nos da una prueba más del lugar preferencial qué la magia ha ocupado en la vida de los judíos del mundo mediterráneo ${ }^{40}$. Uno de

30 Véase nota 9

40 Sobre la documentación médica de la Gueniza véase GoITEIN, S. D., «The medical profession in the light of the Cairo Geniza Documents", Hebrew Union College Annual, vol. XXXIV, 1963, págs. 177-194; y sobre todo la amplia obra de GoTTHEIL, R., «A Further Fragment on 
los ejes interesantes de la investigación futura debe ser un estudio comparativo de las prácticas mágicas en el Oriente y Occidente. Los documentos de la Gueniza representan todas las lenguas judías escritas en esta época: árabe, judeo-árabe, hebreo, judeo-español y, en algunos casos, también el Yidish. Una cantidad considerable de estos documentos contienen información valiosa sobre las prácticas médicas entre los siglos $\mathrm{XI}-\mathrm{XV}$. Pero casi todos los investigadores que estudian hoy este tesoro de documentación no se ocupan de la historia de la medicina ${ }^{41}$. Sin duda es un campo nuevo para quienes el tema les interese.

\section{LA MEDICINA JUDEO-ESPAÑOLA DESPUÉS DE 1492}

La medicina judeo-española no fue eliminada en 1492. La profesión médica siguió siendo importante tanto entre los judeo-conversos en España y en Portugal, como entre los judíos emigrados de la Península Ibérica. Hasta hoy no existe un estudio amplio y serio de estos dos gru$\operatorname{pos}^{42}$.

El estudio histórico-sociológico de L. García Ballester sobre Los moriscos y la medicina, antes citado, atestigua la degradación del médico y la medicina moriscos: "Los sanadores moriscos, desvinculados de sus fuentes originales, reducidos - las más de veces- a unas condiciones de vida propias del peonaje campesino, sometidos a todo tipo de presiones sociales, políticas y religiosas, desaparecido el freno de la enseñanza científica y libre y de la presencia de profesionales científicos, se convirtieron inevitablemente en curanderos ${ }^{43}$. Los médicos judeo-conversos,

Medicine from the Genizah in Cairo", Mélanges Maspéro, III: Orient Islamique, 1935-1940, págs 173-176; "Fragments of a Short Medical Vocabulary from the Cairo Geniza", Jewish Quarterly Review, vol. XXVI, 1935-1936, págs. 7-27; "A Fragment from a Treatise on Medicine", Jewish studies in memory of George A. Kohut. Nueva York 1935, págs. 315-324; "Further fragments on medicine from the Geniza», Jewish Quarterly Review, vol. XXI, 1930-1931, págs. 419-438; «Fragments treating of medicine from the Cairo Geniza", Journal of the American Oriental Society, vol. L, 1930, págs. $112-124$.

41 C. Crews dedicó algunos trabajos a la medicina en judeo-español: “One Hundred Medical Recipes in Judeo-Spanish of ca. 1600», Revue des étucies juives, vol. CXXVI, 1967, págs. 203263; "A Judeo-Spanish Medical Ms. (ca. 1400-1450)", Vox Romanica, vol. XXII, 1964, págs. 192218; "Corrigenda in 'Á Judeo-Spanish Medical Ms...'”, ibidem, vol. XXIV, 1965, págs. 132-133.

42 BaLABAN, M., Juedische Aertze und Apotheker aus Italien und Spanien im XVI und XVII Jahrhundert In Krakau. Czernowitz 1912; HALÉVY, M. A., "Médecins juifs d'origine hispano-portugaise dans les pays roumains", Revue d'histoire de la médecine hébraïque, vol. XXXV, 1957, págs. 21-30; KARChER, J., «Die jüdischen Arztphilosophen Spaniens und Lusitaniens vom Mittelalter bis zur Neuzeit», Gesnerus, vol. IX, 1952, págs. 124-148.

43 García Ballester, Los moriscos y la medicina, págs. 212. 
en cambio, continuaban, generalmente, ejerciendo la medicina científica, como fue el caso famoso de la familia de Castro. «Cristianos nuevos» de origen judío han mantenido su educación científica y su prestigio social, aunque fueron también sometidos a las presiones sociales (antagonismo con los «cristianos viejos", competición con los médicos de ese origen, etc.), religiosas (sospechosos durante generaciones de cualquier contacto con el judaísmo) ${ }^{44}$. ¿Cómo se explica este desarrollo en direcciones opuestas de los médicos moriscos y los judeo-conversos? La documentación sobre los judeoconversos, como muestra la obra de Carlos Carrete Parrondo, es abundante en los diversos archivos. Una investigación de este carácter es necesaria y nos permitiría aprender mucho sobre la sociedad judeo-conversa. Aparte de la documentación de los archivos, existen también los tratados médicos de los judeo-conversos. El análisis y la publicación eventual de los manuscritos pueden arrojar luz sobre la cultura médica y el nivel científico de estos médicos.

Algunos trabajos fueron hechos sobre los judeo-conversos portugueses $^{45}$. El último, hasta este momento no publicado, fue realizado por Reuben Feingold. La fuente de ese trabajo es una lista de 70 médicos judeoconversos escapados del territorio portugués, escrita en el año 1614. Al lado de datos importantísimos sobre estos médicos y cirujanos -como, por ejemplo, que esta clase de médicos constituían la mayoría de los que ejercían las profesiones médicas en la dicha época-, la lista nos ofrece una valiosa información sobre su educación, genealogia, sus mujeres, sus hijos, lugar de nacimiento, etc. Curiosamente esta fuente ofrece también descripciones físicas y upsicológicas» de los citados médicos y sus familias. Así, por ejemplo, nos informa que la mujer de Gasper López era de cuarenta años de edad, que tenía la cara pálida y mórbida, la boca tortuosa y sin dientes, la nariz torcida y hablaba de manera extraña. Es verdad que este tipo de documentación es rara, pero muestra las posibilidades escondidas en los archivos.

La segunda corriente trata de los médicos judeo-españoles expulsados, su actividad médica en los países de exilio y su contribución a la ciencia médica en estos países. Tampoco en este campo la investigación es amplia. Sólo algunos artículos escritos hasta hoy, que aportan una información insuficiente. Uno de los aspectos importantes, que la búsqueda

44 Millás y Vallicrosa, J. M., "La obra médica de la familia toledana de los Castro", en su: Estudios sobre la historia de la ciencia española. Barcelona 1949, págs. 443-454.

45 Silva Carvalho, A. da, Noticia sobre alguns medicos judens do Alentejo. Lisboa 1930; Friedenwald, H., "Jewish Physicians of Spain and Portugal: Historical Notes and Anecdotes", Medical Life, vol. XLV, 1938, págs. 205-220. 
puede aportar, es de la herencia médica que estos médicos judíos llevaban de España a su nueva patria. Estoy examinando este aspecto a través del estudio de un tratado sobre la pestilencia. El autor del tratado es llyās al-Yahūdī ibn Ibrhīm al-Isbānī, y es dedicado al sultán otomano Bayazid. Es significativo que esta generación de médicos judíos continuaban escribiendo en lengua árabe, con algunas faltas gramaticales, pero árabe literario de nivel bastante culto. Se puede concluir que los autores judíos españoles guardaban la tradición médica árabe, existe una línea persistente entre Kitāb al-ț ibb al-qaš ț alī, escrito por un judío anónimo en los años de transición del siglo XIII al XIV, Guerem ha-ma calot, de Yehošu ${ }^{\circ}$ ha-Lorqī, escrito originalmente en árabe en el principio del siglo XV, y este tratado de pestilencia, escrito también en árabe, en el siglo XVI. Además, el autor de este último libro era muy familiar tanto con los autores clásicos como los autores españoles de la Edad Media, él aporta la tradición médica española, musulmana, cristiana y judía al imperio otomano.

Los horizontes de investigación sobre la medicina judía española, que he presentado en esta exposición, se relacionan estrechamente con la medicina musulmana y cristiana. La transmisión de ideas y el corpus médico en la Edad Media, ignoraban las fronteras políticas, los límites religiosos y los confines culturales. Por tanto, es imposible tratar la medicina judía y los médicos judíos como un fenómeno aislado, sino a partir de una visión compleja de relaciones inter-culturales. El estudio de la medicina cristiana y musulmana avanzó considerablemente en los últimos años, mientras que el estudio de la medicina judía quedó muy limitado. El progreso de ese estudio no puede basarse en el esfuerzo de individuos. Me parece útil crear una sociedad internacional para el estudio de la historia de la medicina judía, que se encargue de la coordinación de las investigaciones, de las publicaciones a nivel académico y de la organización de encuentros internacionales sobre el tema. 